\title{
Aus dem Vorwort zur elften Auflage
}

Die wissenschaftliche Medizin verwendet so viel Kunstansdräcke und Fremdwörter, daB es auch dem Belesenen unmöglich ist, sie im Gedăchtnis zn bewahren. Das gilt noch besonders von den zahlreichen Krankheiten, Zeichen usw., die mit dem Eigennsmen des Entdeckers benannt werden.

Dies Băchlein stellt deshalb die gebrauchlichen Fremdworter mit kurzer Angabe der Ableitung und der Bedentung und die wichtigsten Kunstausdrticke ans den alten und ans den neuen Sprachen zusammen. Dabei ist tuberall mehr Wert daranf gelegt worden, die Worter zu bringen, die dem Leser begegnen, als Bezeichnungen zu sammeln, die einzig ihr Frfinder und nie ein anderer verwendet hat. Durch knappe Fassung der Errklarungen und durch Verzicht anf zwecklose Anfthrung anatomischer, zoologischer usw. Namen konnte bei geringem Umfang eine sehr grobe Zahl von wichtigen Stichworten behandelt werden.

Wiesbaden, Oktober 1922

\section{Der Verfagser.}

\section{Vorwort zur dreizehnten und vierzehnten Auflage}

Durch den inzwischen erfolgten Tod des Kollegen Dornblüth war die Bearbeitung der vorliegenden Auflage durch einen anderen erforderlich. Wenn nun auch wesentlich im Sinne des Toten weitergearbeitet werden soll, so ergab sich doch die Notwendigkeit eingreifender Ānderungen: Es muBte den neueren serologischen und allgemein biochemischen Fragen ein weiterer Raum als seither zugebilligt werden. Dadurch hätte das Büchlein seinen Umfang wesentlich überschritten und 